\title{
EAR FINDINGS IN POST SURGICAL CLEFT PALATE PATIENTS
}

\author{
Thakur SK, ${ }^{1 *}$ Yadav $B,{ }^{1}$ Bedajit $R K,{ }^{2}$ Shrestha $K K,{ }^{3}$ Rai $S M^{4}$
}

\section{Affiliation}

1. Lecturer, Department of ENT, Nobel Medical College, Kanchanbari, Biratnagar.

2. Professor, Department of ENT, Nobel Medical College, Kanchanbari, Biratnagar.

3. Coordinator (Public Health Program), Edenburgh International College, Biratnagar.

4. Professor, National Academy of Medical Sciences, and Senior Consultant, PHECT NEPAL, Kathmandu

\section{ARTICLE INFO}

\section{Article History}

Received : 10 February, 2019

Accepted : 23 April, 2019

Published : 30 April, 2019

(c) Authors retain copyright and grant the journal right of first publication with the work simultaneously licensed under Creative Commons Attribution License CC - BY 4.0 that allows others to share the work with an acknowledgment of the work's authorship and initial publication in this journal.

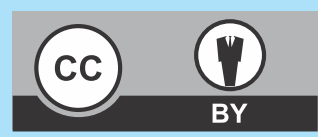

\section{ORA 102}

\section{DOI: http://dx.doi.org/10.3126/bjhs.v4i1.23934}

\section{* Corresponding Author}

Dr. Sanjeev Kumar Thakur Lecturer

Department of ENT, Nobel Medical College, Biratnagar, Nepal Email: sanjeevkr055@gmail.com ORCID ID: http://orcid.org/0000-0002-2855-1766

\section{Citation}

Thakur SK, Yadav B, Bedajit RK, Shrestha KK, Rai S M. Ear Findings in Post Surgical Cleft Palate Patients. BJHS 2019;4(1)8: 621 - 624.

\section{ABSTRACT}

\section{Introduction}

Cleft lip and palate is one of the most common congenital anomaly, which contributes to eustachian tube dysfunction leading to impaired middle ear ventilation and middle ear pathology. It has been stated that the timely repair of cleft palate reduce the incidence of otitis media with effusion.

\section{Objective}

To describe the ear findings in cleft palate patients who have undergone repair of cleft palate.

\section{Methodology}

36 ( 20 male and 16 female) post cleft repair patients underwent Otoscopy and Tympanometry between January to December 2018. Cases with isolated cleft lip, ears with perforation of tympanic membrane and attico-antral disease were excluded.

\section{Results}

The age range was from 4 years to 24 years, with a mean of 11.34 years. Maximum patients were of the age group of $10-$ 20 years $(18,50 \%)$ followed by that of $5-10$ years range $(15$, $41.66 \%)$. Total number of ears examined were 72 . Out of a total of 72 ears, $70(97.2 \%)$ had abnormal otoscopic finding with dull tympanic membrane in 37 (51.39\%) ears, retracted in 31 (43.05\%) and bulging tympanic membrane in 2 (2.78\%) cases. Type B curve was the commonest $(36,50 \%)$, followed by Type As (24, 33.3\%). Type C curve was found in 11(15.3\%) ears. Type A curve was found only in 1 ear. The duration of post-repair of cleft palate ranged from 6 months to upto 16 years with a mean of 8.52 .11 cases(30.56\%) had history of repair of cleft palate of more than 10 years duration. 16 cases $(44.44 \%)$ had that of more than 5 years and 9 cases (25\%) had less than 5 years history of duration of repair. When correlation was done statistically, the tympanometry findings and duration of repair had a very low correlation (Table 5). The time period of repair had no significant effect on tympanometric ear findings.

\section{Conclusion}

Abnormal otoscopic findings and tympanometric findings were common in post cleft palate repaired patients. The duration of cleft palate repair had low correlation to the tympanometric ear findings.

\section{KEYWORDS}

Cleft palate, middle ear, otoscopy, tympanometry 


\section{INTRODUCTION}

Cleft lip and palate are common congenital anomaly with a birth prevalence rate ranging from $1 / 1000$ to $2.69 / 1000{ }^{1}$ There is a high association of middle ear pathology and cleft palate, when left unrepaired. Basic pathophysiology that contributes to deafness in these children is eustachian tube dysfunction leading to impaired middle ear ventilation. This can progress to otitis media with effusion (OME), acute suppurative otitis media, and chronic suppurative otitis media.

It has been stated that the children with cleft palate who have not being repaired up to the advanced age, will have otitis media with effusion or its further complications, more frequently in comparison to those having normal palate. ${ }^{2,3}$ Timely repair of cleft palate has been proposed to improve middle ear physiology and reduce the incidence of otitis media with effusion. ${ }^{4}$ However, this opinion has been challenged in some literature.

Otoscopy is a basic primary modality of evaluation of external auditory meatus and the tympanic membrane (TM). This also helps in diagnosing the middle ear pathology. Tympanometry is an objective test to assess middle ear function. It is the gold standard investigation in detecting otitis media with effusion. The type of tympanometric curve obtained is classified according to the Lidén and Jerger's classification. ${ }^{7,8}$ The classification of these curves is: a. Type A: Suggestive of normal middle ear function b. Type AS: Suggestive of a less compliant middle ear system c. Type Ad: Suggestive of highly compliant middle ear system d. Type B (low and high): Lowsuggestive of middle ear dysfunction, high-suggestive of grommet or perforation e. Type C: Suggestive of eustachian tube dysfunction. Type A curve is considered normal and all others (Types B, C, As, and Ad) as abnormal.

This study was conducted on patients of cleft palate, with or without cleft lip who have underwent repair, to evaluate the middle ear function in postoperative period.

\section{METHODOLOGY}

The patients included in the study were the postoperative cases of cleft palate, with or without cleft lip, attending ENT OPD for check up from 1 January to 31 December 2018. These cases were evaluated in the OPD, after ethicalapproval and informed consent. A total of 36 cases were included in the study group (20 male and 16 female) after fulfilling the criteria. For the purpose of analysis, the results obtained were expressed as number of ears. Otoscopy and tympanometry was done in all patients. Otoscope examination was done with Welch Allyn Otoscope. Ears with perforation of tympanic membrane and attico antral disease were excluded.

Tympanometry was done with Impedence audiometer AT235 Interacousticus A/S Assens (Denmark) with universal probe system ATP-AT235U. Probe tone frequency was $226 \mathrm{~Hz}$ and probe tone intensity was $85 \mathrm{dBSPL}$. The results were tabulated and analysed. Spearman's correlation was done to that of the duration of repair of cleft palate and the tympanometric finding of ear, using IBM SPSS statistics 21.0 version.

\section{RESULTS}

A total of 36 ( 20 male, 16 female) patients of cleft palate,

with or without cleft lip were included. The age range was from 4 years to 24 years, with a mean of 11.34 years+/- 4.34 (Table 1). Maximum patients were of the age group of 10-20 years $(18,50 \%)$ followed by that of $5-10$ years range $(15$, $41.66 \%$ ). Total number of ears examined were 72.70 ears had abnormal otoscopic finding with dull tympanic membrane in 37 (51.39\%) ears, retracted in 31 (43.05\%) and bulging tympanic memebrane in 2 (2.78\%) cases (Table 2$) .2$ (2.78\%) ears were absolutely normal. Type B curve was the commonest (36, 50\%), followed by Type As (24, 33.3\%) Table 3. Type C curve was found in 11(15.3\%) ears. Type A curve was found only in 1 ear. The duration of post-repair of cleft palate ranged from 6 months to upto 16 years with a mean of $8.52+/-4.25$ (Table 4$) .11$ cases(30.56\%) had history of repair of cleft palate of more than 10 years duration.16 cases $(44.44 \%)$ had that of more than 5 years and 9 cases (25\%) had less than 5 years history of duration of repair. When correlation and association was done statistically, the tympanometry findings and duration of repair had no significant correlation or association (Table 5).

Table 1: Age Distribution
\begin{tabular}{|c|c|c|}
\hline $\begin{array}{c}\text { AgE GROUP } \\
\text { (years) }\end{array}$ & NUMBER & PERCENTAGE \\
\hline$\leq 5$ & 2 & 5.56 \\
\hline$>5-10$ & 15 & 41.66 \\
\hline$>10-20$ & 18 & 50 \\
\hline$>20$ & 1 & 2.78 \\
\hline TOTAL & 36 & 100 \\
\hline
\end{tabular}

Table 2: Otoscopic findings
\begin{tabular}{|l|c|c|}
\hline Otoscopic findings ( $\mathbf{n = 7 2 )}$ & Number & Percentage \\
\hline Normal & 2 & 2.78 \\
\hline Dull Tympanic membrane (TM) & 37 & 51.39 \\
\hline Bulging of TM & 2 & 2.78 \\
\hline Retraction of TM & 31 & 43.05 \\
\hline Total & 72 & 100 \\
\hline
\end{tabular}

Table 3: Type of Tympanometry curve
\begin{tabular}{|c|c|c|c|c|}
\hline $\begin{array}{c}\text { Type of } \\
\text { Curve }\end{array}$ & $\begin{array}{c}\text { Right ear } \\
\text { (Number) }\end{array}$ & $\begin{array}{c}\text { Left ear } \\
\text { (Number) }\end{array}$ & Total & Percentage \\
\hline A & 1 & 0 & 1 & 1.4 \\
\hline As & 12 & 12 & 24 & 33.3 \\
\hline B & 16 & 20 & 36 & 50 \\
\hline C & 7 & 4 & 11 & 15.3 \\
\hline Total & 36 & 36 & 72 & 100 \\
\hline
\end{tabular}

Table 4: Duration of Repair
\begin{tabular}{|c|c|c|}
\hline $\begin{array}{c}\text { DURATION OF } \\
\text { REPAIR (years) }\end{array}$ & NUMBER & PERCENTAGE \\
\hline$\leq 5$ & 9 & 25 \\
\hline$>5-10$ & 16 & 44.44 \\
\hline$>10-20$ & 11 & 30.56 \\
\hline TOTAL & 36 & 100 \\
\hline
\end{tabular}

Table 5: Duration of repair of cleft palate to Tympanometry findings (Correlation and association)

$n=72$

Spearman's Correlation
coefficient (rho value) Chi-Square value
Right tympanometry

$r=-0.005$
Left Tympanometry

$r=-0.139$ 


\section{DISCUSSION}

Cleft lip and palate are congenital deformity caused by abnormal facial development during gestational period. Cleft palate is a condition in which two plates of skull that forms the hard palate (roof of mouth) are not completely formed. Cleft palate can be of two types: complete (hard palate and soft palate) or incomplete (a hole in the roof of mouth). The basic defect is failure of fusion of the lateral palatine processes, the nasal septum and/or the median palatine processes.

The mean age of 36 (20 male, 16 female) patients of study group was 11.34 years. The mean duration of cleft repair was 8.52 years. $70(97.22 \%)$ ears had abnormal otoscopic finding (dull TM 51.39\%, retraction $43.05 \%$, bulging TM 2.78\%). Abnormal tympanometric finding was found in 71(98.6\%) ears(Type B 50\%, Type As 33.3\%,Type C 15.3\%) . Feniman et al. observed $84 \%$ of alterations in otoscopy (opacification $-83.4 \%$, visible fluid in the middle ear-1.5\%, the eardrum does not move during inflation-1.8, and retraction - 0.7) and $65 \%$ in tympanometric curves $(B / 38 \%$, $\mathrm{A} / 36.5 \%, \mathrm{As} / 21 \%, \mathrm{C} / 4 \%$, and $\mathrm{Ad} / 0.5 \%)$ in their study. ${ }^{9}$ Zheng et al. had abnormal tympanometry in $52 \%$ of the ears examined and eardrum retraction was found to be to be the most common otoscopic abnormality (50\%). ${ }^{10}$

Similar was the observation of Gautam et al. who found abnormal otoscopy in $66.6 \%$ and Type B tympanogram in $72.7 \%$ of the ears they evaluated. ${ }^{11}$

In developing and underdeveloped countries, children with cleft palate are ignored till a later age. The various reasons for this could be poverty, illiteracy, and most importantly ignorance on the part of parents about its effect on speech and middle ear function. The other reason could be their apprehension about anesthesia and surgery. This is evident from the study involving elderly patients having unrepaired cleft palate. $^{10}$

The management of cleft lip and palate have focused more in the direction of palatal reconstruction and lip repair to achieve cosmetic acceptability and palatal function for speech and deglutition. However, these patients are at risk of several other problems along with the conductive hearing loss also. The highly significant association of hearing loss and cleft palate highlights the importance of the role of the otolaryngologists in the management of these patients. There are less reports on the comparative study of middle ear status of cleft palate patients operated at an early age and those not operated till an advanced age. Tuncbilek found the prevalence of middle ear disease in post repair cleft palate children to be much lower than the no palatoplasty group. ${ }^{4}$ Too-Chung also concluded that early closure (before 4 months of age) of the palatal defect reduced middle ear complications significantly. ${ }^{12}$ Dhillon suggested that the incidence of otitis media with effusion is marginally reduced by palatal surgery and Goode T tube provides a satisfactory method for long term middle ear ventilation. $^{3}$

More than $75 \%$ of cases had history of repair of more than 5 years duration in our study. However, on statistical analysis, the duration of repair had no significant effect on middle ear status as revealed by the tympanometric findings, and there was no correlation and association.
Gopalakrishna et al. found cleft palate repair to have no significant effect on the high incidence of serous otitis media in this subset of patients, similar to our study. ${ }^{13}$ However, they included a third subgroup of children having normal palate and observed them to have a lower incidence of serous otitis media in comparison to the children having cleft palate. Similar observation was also made by Lokman et al. who found no significant difference between the incidence of middle ear effusion in unrepaired and repaired cleft palates. ${ }^{14}$ Lima et al. also compared three groups of children - those with cleft palate and low birth weight, cleft palate and normal weight, and the third with normal palate and normal weight. ${ }^{15}$ They found no significant difference among these three groups in terms of tympanometry.

Holborow was of the opinion that the tensor palatine muscle is ineffective in its role of opening the nasopharyngeal end of the Eustachian tube in causation of middle ear abnormalities. ${ }^{16}$ This defect in mechanism resulted in inadequate ventilation of the middle ear and the resulting otitis media with effusion. Bluestone et al, supported this hypothesis by roentgenographic study. ${ }^{17}$ Shprintzen conducted fiber-optic nasopharyngoscopy in patients of cleft palate. He suggested hypoplasia of cartilage at pharyngeal end of eustachian tube, small size of opening, and inability to maintain patency during deglutition as the causes of eustachian tube dysfunction. ${ }^{18}$

Mechanical cause like the abnormal reflux of food and fluid into the nasal cavity can possibly set up chronic inflammatory changes around the Eustachian orifices with oedema, hypertrophy of adenoid pads, low-grade obstruction, and secondary middle ear disease. The break in the mechanical barrier between the mouth and nasopharynx with its concomitant chronic inflammatory change could alter the bacterial flora of the region to permit overgrowth of predominately pathogenic bacteria. The dynamic factor of Eustachian tube and middle ear physiology depends upon an intact Eustachian apparatus and relatd extrinsic musculature. In the normal resting phase, the Eustachian orifices are closed which opens widely with yawning and swallowing, and also opens slightly with normal speech. This opening of the Eustachian orifice permits pressure equalization through aeration and is dependent upon the action of the intact tensor and levator palatini muscles. The rapid motion of these muscles, particularly during speech, may produce a milking action in the cartilaginous portion of the Eustachian tube. Thus, the dilation of the orifices depends upon muscles which are not intact in those children with a cleft palate. This dynamic function of the tensor and levator muscles is well known in speech as velopharyngeal closure that largely depends upon their contraction, but the secondary opening and closing of the eustachian orifices may be of equal importance in the prevention of hearing loss and middle ear pathology.

At rest the eustachian tube remains closed. When open, it ventilates the middle ear, releases mucus and equalizes pressure differentials that are created by gaseous absorption and environmental pressure changes. In children with an unrepaired cleft palate, the tensor muscle fibres do not have a normal course and midline palatal insertion and, 
therefore, lack the anchorage to effectively open the eustachian tube. In this situation, when gases are absorbed by the mucous membrane of the middle ear they are not replaced, resulting in negative pressure. Sustained negative pressure results in a retracted tympanic membrane and eventual secretion of fluid into the middle ear space from the mucous membrane. ${ }^{19}$

Kemaloglu et al. have analyzed the craniofacial skeleton and have suggested that there are many factors in the skeleton that predispose these children to Otitis Media with Effusion(OME). They concluded that the small dimensions of the posterior cranial base (spheno-occipital bone) and backward and upward position of the maxilla were associated with tendency to OME in clefts. In addition, mastoid depth and height were also shorter in cleft cases than normal subjects. On the other hand, a small tendency to recurrent upper airway infection (RUAI) was observed in cleft cases with OME. Further, it was found that the following differences in the mastoid-middle ear-Eustachian tube (M-ME-ET) system were associated with a tendency to OME in unilateral cleft lip and palate UCLP cases: more horizontal ET in relation to the posterior cranial base; short bony ET; short height and antero-posterior depth of the mastoid air cell system. ${ }^{20}$

\section{CONCLUSION}

Abnormal otoscopic findings and tympanometric findings were common in post cleft palate repaired patients. The duration of cleft palate repair had low correlation to the tympanometric ear findings. Small study sample could have influenced the outcome of this study. There could also be other possible factors affecting eustachian tube function apart from cleft palate and tensor veli palatini muscle abnormality in cleft palate patients. Further detailed research has to be undertaken in this direction.

\section{RECOMMENDATION}

Preoperative as well as postoperative ENT check up and audiological assessment should be done regularly in patients with cleft palate. Cases with otitis media with effusion should be identified and myringotomy and grommet insertion done before palatal surgery. Team approach would definitely lead to a favorable outcome in the management of these patients.

\section{LIMITATION OF THE STUDY}

This study was done in a small sample of cases. Further exploration in to different causes of Eustachian tube dysfunction should have been analysed.

\section{ACKNOWLEDGEMENTS}

We are grateful to the team of PHECT NEPAL and Nobel medical college staff for their help and support.

\section{CONFLICT OF INTEREST}

None

\section{FINANCIAL DISCLOSURE}

\section{None}

11. Gautam P, Sharma R, Prakash A, Kumar S, Taneja V. Assessment of middle ear function in patients with cleft palate treated under "Smile Train Project". Indian J Otol 2011;17:105 8. DOI: 10.4103/09717749.91186

12. Too Chung MA. The assessment of middle ear function and hearing by tympanometry in children before and after early cleft palate repair. Br J Plast Surg 1983;36:295 9. 23. PMID:6860854.

13. Gopalakrishna A, Goleria KS, Raje A. Middle ear function in cleft palate. Br J Plast Surg 1984;37:558 65.PMID: 6541954.

14. Lokman S, Loh T, Said H, Omar I. Incidence and management of middle ear effusion in cleft palate patients. Med J Malaysia 1992;47:51 5.PMID: 1387450.

15. Lima AM, Lauris JR, Feniman MR. Hearing in children with cleft lip and palate and low weight: Comparative study. Int Arch Otorhinolaryngol 2011;15(4):461-7.DOI: 10.1590/S1809-48722011000400009.

16. Holborow CA. Deafness associated with cleft palate J Laryngol Otol 1962;76:762-73. https://doi.org/10.1017/S002221510006000X.

17. Bluestone CD, Wittel RA, Paradise JL. Roentgenographic evaluation of Eustachian tube function in infants with cleft and normal palate (with special reference to the occurrence of otitis media). Cleft palate J 1972;9:93-100. PMID:4504272.

18. Shprintzen RJ, Croft CB. Abnormalities of the Eustachian tube orifice in individuals with cleft palate. Int J Paediatr Otorhinolaryngol 1981;3:15-23. PMID:7203806.

19. Masters FW, Bingham HG, Robinson DW. The prevention and treatment of hearing loss in the cleft palate child. Plast Reconstr Surg. 1960;25:503-9. PMID:14422178.

20. Kemaloglu YK, Kobayashi T, Nakijama T. Analysis of craniofacial skeleton in cleft children with otitis media with effusion. Int J Pediatr Otolaryngol. 1999;47:57-69. PMID:10206395. unrepaired cleft palate. Cleft Palate Craniofac J 2009;46:24 9. PMID 19115794. 